\title{
Decolonizando os Discursos Midiáticos a Partir das Relações Internacionais: \\ 0 protagonismo brasileiro no acordo de Teerã na visão do jornal $O$ Globo
}

\author{
Leonardo Rocha Lupi ${ }^{1}$
}

\section{Resumo}

Através da perspectiva decolonial e da metodologia de análise do discurso, o artigo tem como objetivo examinar a construção discursiva do jornal O Globo sobre o protagonismo assumido pelo Brasil no Acordo de Teerã (2010). Por meio da análise de editoriais, o artigo levanta a seguinte reflexão: de que forma os grandes veículos jornalísticos brasileiros enxergam o papel do país no cenário internacional? No caso do Acordo de Teerã, identifica-se que o tema foi tratado com forte crítica à atuação do governo. A defesa constante do jornal de um maior alinhamento com os Estados Unidos e a crítica ao adensamento de relações com outras nações emergentes explicitam a colonialidade presente no discurso da mídia comercial. Sendo O Globo pertencente a um dos maiores grupos de comunicação do país, é necessário compreender a configuração histórica, política e econômica da imprensa nas sociedades latino-americanas. Propondo uma interseção entre os estudos de Mídia e de Relações Internacionais, dada a mútua influência entre as áreas, o artigo reflete sobre as diferentes visões de política externa e protagonismo global existentes neste caso: entre o governo, entusiasta do tratado, e a imprensa comercial, crítica de que o Brasil tomasse a frente do Acordo sem o aval norte-americano.

Palavras-chave: decolonialidade - Acordo de Teerã - política externa - mídia - O Globo

\section{Abstract}

From a decolonial perspective and based on the methodology of the discourse analysis, this paper aims at examining the discourse construction of $O$ Globo about the Brazilian leadership in the Tehran Declaration (2010). From the analysis of editorials, this article raises the following reflection: how do the big Brazilian newspapers see the role of the country in the international scenario? The role the Brazilian government played in the Tehran Declaration was strongly criticized by the media. Coloniality is present in the discourse of $O$ Globo in the constant defense of an alignment with the United States politics as well as in the opposition to the increasing relations with other emergent nations. As O Globo is one of the biggest and most powerful communication groups in Brazil, it's necessary to study the political, economic and historical configuration of the media in Latin American societies. The article suggests an intersection between the Media and the International Relations studies, given their mutual influence. It also reflects about

\footnotetext{
1 Graduado em Comunicação Social-Jornalismo pela Universidade Federal do Rio de Janeiro (UFRJ). E-mail: leonardo.rocha.lupi@gmail.com.
} 
the different views on external politics and global leadership existing in this case: between the government, who furthered the Tehran Declaration, and the corporate media, who criticized the Brazilian participation in the agreement without the North American endorsement.

Keywords: decoloniality - Tehran Declaration - external politics - media - O Globo

\section{Introdução}

O objetivo deste artigo é realizar uma análise crítica decolonial do discurso da chamada "grande imprensa", a partir de editoriais do jornal O Globo que tenham abordado o papel do Brasil nas negociações do Acordo de Teerã, em 2010. Ao se optar pela teoria decolonial, entende-se que a opinião difundida pelos editoriais partia de uma visão contaminada pela colonialidade.

A Declaração de Teerã, assinada por Brasil, Turquia e Irã, é o documento final de uma série de negociações a respeito do programa nuclear iraniano. Visando uma solução diplomática para a crise entre o país árabe e o Conselho de Segurança da ONU, o governo brasileiro atuou fortemente em tais mediações. A atuação brasileira foi amplamente criticada em jornais impressos de grande circulação, como O Globo.

Uma vez que se trata de um fato recente da diplomacia brasileira e que o objetivo é questionar a posição da mídia comercial, foi feita a escolha pela teoria decolonial e por autores como Arturo Escobar (2007), Ramón Grosfoguel (2007) e Walter Mignolo (2010). O objetivo é privilegiar visões latino-americanas e periféricas em detrimento do arcabouço teórico anglo-saxão tão comum nos trabalhos de RI e de Mídias.

A opção por unir estudos de Mídias e Relações Internacionais se dá pelo entendimento de que o encontro entre as áreas deve ser aprofundado, dada a interseção de temas e a mútua influência das disciplinas. Apontar a interferência do jornalismo na política externa, bem como a instrumentalização da mídia pela diplomacia, é de fundamental importância para a compreensão da análise proposta.

A metodologia utilizada para o estudo dos editoriais de O Globo é a análise de discurso. Ao todo, dos vinte e um editoriais que abordavam a questão iraniana publicados no ano de 2010, cinco, na visão deste autor, representam a linha de pensamento que pautou as críticas à atuação do Brasil. 
A primeira parte do artigo apresenta um breve histórico sobre a teoria decolonial, ressaltando a necessidade de se "decolonizar" os estudos de Mídia e RI no Brasil. A segunda, por sua vez, trata do contexto político, apontando as nuances da diplomacia do governo Lula e do Acordo de Teerã. Por fim, apresentase a análise de discurso dos editoriais de O Globo, identificando a relação entre colonialidade, mídia e política externa.

\section{Mídia, Relações Internacionais e os Estudos Decoloniais}

A decolonialidade é um termo que surge como terceiro elemento dos estudos de modernidade/colonialidade, e que significa a resistência - teórica e prática - a estes dois fenômenos. O grupo Modernidade/Colonialidade, responsável pelo estudo inicial de tais conceitos, foi estruturado na América Latina nos anos 1990 por meio de seminários, reuniões e publicações, promovendo o diálogo entre acadêmicos de diferentes áreas das ciências humanas como Filosofia, Sociologia, Antropologia, Linguística e Semiótica (BALLESTRIN, 2013, p.90-99). O grupo herdou influências de linhas de pensamento já formuladas por alguns desses estudiosos anteriormente, como a Teoria da Dependência e a Filosofia da Libertação. Também há uma clara e expressiva influência do póscolonialismo e dos estudos subalternos (BALLESTRIN, 2013, p.90-99).

A colonialidade é estudada sob três dimensões: a do poder, do saber e do ser. A colonialidade é definida por Mignolo (2003, p.30) como "o lado obscuro e necessário da modernidade; a sua parte indissociavelmente constitutiva". Partindo do princípio de que o imperialismo e o colonialismo² foram bases fundamentais para o estabelecimento do cenário econômico moderno, é possível afirmar que "não existe modernidade sem colonialidade".

O objetivo dos decoloniais é completar "o sonho inacabado e incompleto do século XX de descolonização" (GROSFOGUEL, 2007, p.221). Para tanto, seria necessário ir além da subjetividade e do saber de origem eurocêntrica, naturalmente limitados para explicar esses processos, porque escondem o sujeito de enunciação. Mignolo (2003) propõe que a decolonialidade deveria se inspirar nos movimentos sociais e nas contribuições latino-americanas e afro-americanas, como o movimento Sem Terras no Brasil, os zapatistas em Chiapas, os

\footnotetext{
2 Colonialismo e imperialismo são conceitos a serem interpretados de diferentes formas. Uma possibilidade para distingui-los é separá-los em termos espaciais e não temporais. Desta forma, imperialismo ou neoimperialismo seria o movimento de dominação que se origina na metrópole, e sua consequência nas colônias configuraria o colonialismo ou neocolonialismo. O colonialismo só diz respeito a colônias formais, enquanto o imperialismo pode existir sem estas - a exemplo do imperialismo norte-americano atualmente (LOOMBA, 1998, p.6).
} 
movimentos indígenas e afros na Bolívia, Equador e Colômbia, o Fórum Social Mundial e o Fórum Social das Américas (BALLESTRIN, 2013).

Algumas críticas feitas à teoria decolonial giram em torno de um suposto maniqueísmo e de uma visão romantizada do "oprimido". Alguns críticos apontam ainda uma sobrevalorização da questão étnica em detrimento da luta de classes, bem como um "descarte" radical e integral da modernidade (BALLESTRIN, 2013, p.111). As maiores limitações da teoria decolonial estariam na dificuldade de se mensurar a colonialidade no mundo atual. Mesmo as instituições vistas a princípio como decoloniais não estariam necessariamente livres de contradições (BALLESTRIN, 2013, p.110-112).

Para a compreensão da interseção proposta, é fundamental entender o papel da mídia nas relações internacionais e na política externa. A mídia, enquanto formadora de opinião pública ${ }^{3}$, tem uma relevante importância no processo de "significação do mundo, ou seja, na construção social da realidade" (OLIVEIRA, 2010, p.117). Há o entendimento de que, dependendo do contexto, “ora a mídia guia a política, ora a política guia a mídia” (BURITY, 2013, p.173). Pode-se afirmar que "opinião pública e política exterior têm o potencial de se afetar mutuamente" (FARIA, 2008, p.90).

Para contemplar os casos em que a mídia é orientada pela política, pelos governos e pela diplomacia, foi cunhado o termo "diplomacia midiática". A utilização da mídia pelos governantes serve para manifestar interesses, mobilizar a opinião pública e construir confiança para acordos (GILBOA, 2001, p.9-15).

A mídia pode tanto atuar influenciando os temas da agenda política (agenda setting) quanto participando do próprio processo de criação das políticas (policy making) (GILBOA, 2001). A hipótese da agenda setting é de que as escolhas jornalísticas, que dão maior visibilidade a alguns temas e informações em detrimento de outros, têm papel decisivo na formação da opinião pública. Os veículos de comunicação definem para o público uma hierarquia de importância entre os assuntos (VALENTE, 2007, p.63).

É importante destacar o contexto econômico e político em que se inserem as grandes estruturas midiáticas, em especial nos países subdesenvolvidos ou em desenvolvimento. "As fundações de economia política da mídia não mudaram dramaticamente, apesar da diversificação da composição racial na mídia e do

\footnotetext{
3 Por opinião pública, entende-se, de acordo com Lippmann (2008), que esta pode ser administrada segundo a influência de atores poderosos. Trata-se de um "pseudo-ambiente" formulado em nosso mapa mental, através da criação de imagens e da manipulação de afetos pela mídia e pelo noticiário. Trata-se uma administração do consenso social por partes interessadas (LIPPMANN, 2008, p.13).
} 
surgimento de novos conglomerados de mídia locais" (CHIUMBU, 2016, p.422). A estrutura da mídia em nível global está atrelada às regras da globalização, privatização e liberalização, aspectos que são reproduzidos nas imprensas locais.

É possível conceber, também, que a mídia é um canal de reprodução da colonialidade do saber. Os grandes conglomerados de imprensa no Brasil, por exemplo, reproduzem informações das agências de notícia norte-americanas, o que faz com que o brasileiro acabe por ter "uma visão norte-americana dos fatos internacionais" (BURITY, 2013, p.173). Conforme pontua Grosfoguel (2007), o sucesso da modernidade/colonialidade reside exatamente em "fazer sujeitos socialmente localizados no lado oprimido da diferença colonial pensarem epistemicamente como os das posições dominantes" (GROSFOGUEL, 2007, p.213).

Há três pontos que confirmam o jornalismo como difusor de informações enviesadas de cota subjetiva. São eles: existência de uma única via de informação, vinda das mídias dos países desenvolvidos; monopólio de algumas corporações da mídia, que dominam o fluxo da informação no mercado mundial; e, por último, verticalização das notícias que contribuem para uma visão mais distorcida das partes mais pobres do mundo (BURITY, 2013, p.172).

A interseção entre mídia e relações internacionais proposta pelo artigo, justificada acima pela conexão entre os temas, é ainda recente nas academias do Brasil. Segundo Fontes et al. (2017, p.453), "é possível perceber que existe uma ausência dos estudos de mídia e relações internacionais assim como de mídia e política externa".

É preciso destacar também a presença escassa dos autores decoloniais nos currículos de Relações Internacionais no Brasil. Segundo Lessa et al. (2019, no prelo), a produção e o estudo das Relações Internacionais no Brasil praticamente não levam em consideração a contribuição decolonial ou mesmo a pós-colonial, bem como ignora diversas referências latino-americanas. Lessa et al. (2019, no prelo) questiona, inclusive, que sequer se atribui relevância ao estudo da Política Externa Brasileira.

Alguns estudiosos das Relações Internacionais no Brasil apontam, nesta deficiência do currículo brasileiro, a reprodução do que os próprios decoloniais chamariam de colonialidade do saber. Para Quijano (2000), ignorar teorias latinoamericanas faz parte da lógica eurocêntrica de controle da subjetividade e da produção de conhecimento. O monopólio dos teóricos anglo-saxões nos estudos de Relações Internacionais denota não só uma "negligência do Terceiro mundo", 
mas uma implicação da disciplina "em um projeto global que é articulado para servir aos interesses ocidentais" (ESPANHOL, 2017, p.5).

Tal problema não é característico apenas do Brasil, ou mesmo da América Latina. Gonçalves \& Valente (2015, p.69) consideram que "poucos são aqueles países em que o mundo acadêmico pensa as relações internacionais segundo sua própria tradição cultural e segundo seus próprios interesses nacionais". Uma vez que as fundações das relações internacionais são de molde anglo-saxão, podese dizer que há um "predomínio inevitável" da língua inglesa, o que impõe também sua cultura particular e sua visão de sociedade (GONÇALVES \& VALENTE, 2015, p.59).

Para se tornar possível uma decolonização epistêmica das Relações Internacionais no Brasil, é preciso que as grades curriculares e as pesquisas universitárias contemplem com maior abrangência os estudos decoloniais. É necessário contemplar autores como Henrique Dussel, Aníbal Quijano, Ramón Grosfoguel, Arturo Escobar, Boaventura Santos, Walter Mignolo etc.

A busca por uma "autonomia intelectual", nas palavras de Gonçalves \& Valente (2015, p.69), é fundamental enquanto indicador do desenvolvimento de um país. Portanto, pensar as relações internacionais (e também mídias) sob uma ótica decolonial, nas bases da nossa tradição cultural, poderia representar um patamar de autonomia intelectual e nacional (GONÇALVES \& VALENTE, 2015, p.69).

\section{0 protagonismo brasileiro no cenário internacional como ameaça ao mundo} desenvolvido

Para compreender as razões que fizeram com que o protagonismo brasileiro no Acordo de Teerã fosse visto como uma ameaça, é preciso entender a disposição de forças no mundo atual e as origens do que se entende como "potências" e "países periféricos". Para tanto, deve-se compreender os conceitos de desenvolvimento e subdesenvolvimento, a fim de problematizá-los.

De acordo com Arturo Escobar (2007), antropólogo colombiano, o conceito de desenvolvimento é pensado pelos Estados Unidos e pela Europa ao fim da Segunda Guerra Mundial, em 1945, e assimilado pelas elites e governantes do Terceiro Mundo ${ }^{4}$. Tal projeto desenvolvimentista seria, nas palavras de Escobar,

\footnotetext{
${ }^{4}$ Escobar aborda o "Terceiro Mundo" enquanto uma construção feita pelo Ocidente (o "Primeiro Mundo") para hierarquizar sociedades.
} 
"a transformação total das culturas e formações sociais de acordo com os ditames do chamado Primeiro Mundo" (ESCOBAR, 2007, p.11).

As elites dos países periféricos rapidamente assimilaram a crença de que, seguindo o receituário dos países considerados economicamente avançados, poderiam alcançar o mesmo patamar. No entanto, a ideia de que estes "mundos" estão apenas em etapas diferentes da modernização ignora o fato de que, "sem as interações materiais, sociais, intelectuais e culturais com o mundo colonial" nos séculos passados, a Europa não seria o que é hoje (MORENO, 2012, p.46-48).

Tal noção de desenvolvimento, expressa em diferentes dimensões econômica, política, intelectual -, provou manter a lógica de colonialidade existente anteriormente, ainda que agora de maneira mais sutil. Saíram de cena as administrações coloniais formais e a imposição da força militar, e foram empregadas novas ferramentas de manutenção do status quo.

A capacidade dos pobres de definir e governar suas próprias vidas foi corroída ainda mais profundamente do que antes. Os pobres do mundo tornaram-se alvo de práticas cada vez mais sofisticadas e uma multiplicidade de programas aparentemente inescapáveis. Das novas instituições de poder nos Estados Unidos e Europa, dos escritórios do Banco Internacional para Reconstrução e Desenvolvimento e das Nações Unidas, das universidades, centros de pesquisa e fundações norte-americanas e europeias, e dos recém-estabelecidos escritórios de planejamento nas grandes capitais do mundo subdesenvolvido, esse foi o tipo de desenvolvimento que foi promovido e que, depois de alguns anos, penetraria em todas as esferas da sociedade (ESCOBAR, 2007, p.77).

A crítica decolonial é facilmente aplicável ao caso brasileiro. Para Guimarães (2006), as "vulnerabilidades externas" da sociedade brasileira estão estritamente relacionadas "às disparidades internas" e aos "processos de concentração de poder". Tais vulnerabilidades não seriam apenas econômicas, mas também políticas, militares, ideológicas e culturais. Assim como em grande parte da América Latina, a existência de setores internos (elites) que legitimam a dependência externa é um traço marcante do Brasil.

As vulnerabilidades externas associam-se a visões do mundo e da sociedade brasileira, de seu funcionamento econômico e político, e afetam de forma diferenciada, de um lado, os setores beneficiários, e de outro os setores vítimas das disparidades internas. Essas vulnerabilidades decorrem da forma de criação e de expansão da economia capitalista brasileira e de sua inserção na economia mundial; do modo como se estruturou ao longo dos tempos o sistema político brasileiro; de sua inserção no sistema mundial de poder; e do processo de formação da cultura brasileira e de seus vínculos com a cultura mundial, em especial com os centros dinâmicos de sua elaboração e difusão. (GUIMARÃES, 2006, p.22). 
Dentre as muitas vulnerabilidades, Guimarães (2006) destaca a de natureza ideológica. A "colonialidade do saber" estaria expressa por meio desta vulnerabilidade - uma visão de inferioridade do pensamento brasileiro e uma dependência de informação e conhecimento externos.

Os grandes conglomerados de imprensa brasileiros, enquanto formadores de opinião, atuam como parte deste sistema. Como já abordado no início do artigo, as principais empresas de comunicação no Brasil estão inseridas em uma estrutura político-econômica, ou seja, na dimensão da "colonialidade do poder". No entanto, é válido afirmar que, para além do aspecto econômico, há uma reprodução do discurso que insere o mainstream do jornalismo brasileiro na "colonialidade do saber". É a produção de conteúdo jornalístico sob uma perspectiva colonialista (não necessariamente intencional).

Tais características são identificáveis na maior parte das críticas direcionadas à diplomacia brasileira nos governos Lula, uma vez que esta tinha como objetivo perseguir um protagonismo brasileiro no cenário internacional. A política externa "ativa e altiva", segundo expressão cunhada pelo próprio chanceler Celso Amorim, visava assegurar "a capacidade soberana de definir o modelo de desenvolvimento que desejamos para o país" (AMORIM, 2005).

O Itamaraty ${ }^{5}$ no governo Lula tinha como prioridade a integração regional e os laços com os vizinhos sul-americanos (ROSSONE DE PAULA, 2018, p.4). Houve também um significativo adensamento das relações do Brasil com a África, expresso em dois aspectos principais: a cooperação Sul-Sul, com políticas de solidariedade e de combate à pobreza extrema, e a expansão das exportações e o aumento da instalação de empresas brasileiras transnacionais em território africano (BERRINGER, 2014, p.152).

Também merece destaque o fortalecimento de laços com outras nações emergentes como Índia, África do Sul, China e Rússia, que resultou na criação do Ibas $^{6}$ e do BRICS ${ }^{7}$. Para muitos estudiosos, a política externa de Lula permitiu ao Brasil assumir um papel de alta relevância no sistema internacional, contribuindo para a multipolaridade e transformação do jogo de forças (ROSSONE DE PAULA, 2018, p.6).

O esforço mais significativo do governo Lula da Silva é seu papel crescente nas relações internacionais e seu alinhamento do Brasil com as premissas gerais de "desocidentalização", o que envolveu uma "transformação radical" de subjetividades respondendo às diferenças imperiais. Isso significa argumentar

\footnotetext{
${ }^{5}$ Ministério das Relações Exteriores (MRE).

${ }^{6}$ Fórum de Diálogo Índia-Brasil-África do Sul.

7 Brasil, Rússia, Îndia, China e África do Sul.
} 
que o Brasil estava em posição de ajudar a redefinir as geografias da economia mundial e as geografias do conhecimento simultaneamente (ROSSONE DE PAULA, 2018, p.6).

O Brasil foi muitas vezes descrito como uma "ponte" entre as antigas e novas potências, ou entre o mundo desenvolvido e o mundo em desenvolvimento (ROSSONE DE PAULA, 2018, p.6). "O slogan "uma nova geografia para o comércio mundial" adotado pelos países do "Sul" não defendia o isolacionismo em relação ao "Norte", mas pedia um alinhamento entre os países em desenvolvimento" (ROSSONE DE PAULA, 2018, p.7).

Em relação ao Oriente Médio, também se identifica uma aproximação por parte do governo brasileiro. Encontra-se no Brasil a maior comunidade de origem árabe fora do mundo árabe - mais de dez milhões de brasileiros possuem ascendentes na região. A contribuição para a identidade e a cultura brasileiras justificaria, assim, os "sólidos laços de amizade e cooperação que temos com o Oriente Médio" (AMORIM, 2005, n.p.). No âmbito diplomático, destaca-se a intensificação de contato com entidades como a Liga dos Estados Árabes (LEA), organismo regional do qual o Brasil se tornou, em 2003, o primeiro observador latino-americano.

Em relação aos conflitos da região, o Brasil apoiava a criação do Estado Palestino, bem como o direito de Israel por suas terras e sua segurança dentro das fronteiras internacionalmente reconhecidas (BERRINGER, 2014, p.157). Vale lembrar também que o Brasil condenou a invasão do Iraque pelos Estados Unidos em 2003 (BERRINGER, 2014, p.157).

A iniciativa brasileira de negociar com o Irã entre os anos de 2009 e 2010 ocorre em um contexto de mudança de governo nos Estados Unidos após a eleição do democrata Barack Obama, em 2008. Após a dura "Guerra ao Terror" dos governos Bush (2001-2009), que circunscreveu o Irã no chamado Eixo do Mal, havia grande expectativa por uma política de maior diálogo por parte de Obama.

À época, havia grande preocupação internacional devido ao enriquecimento de urânio pelo governo iraniano. Existia um entendimento, por parte das potências ocidentais, de que o Irã havia transgredido normas da Agência Internacional de Energia Atômica (AIEA) ao não notificá-la da intenção de desenvolver energia nuclear (AMORIM, 2015, p.17). É importante ressaltar que o enriquecimento de urânio, em si, é um direito garantido pelo Tratado de Não Proliferação Nuclear (TNP) quando utilizado para fins pacíficos. De acordo com o governo iraniano, a tecnologia serviria para o Reator de Pesquisas de Teerã, que produziria isótopos medicinais para diagnóstico ou até cura do câncer. A 
desconfiança por parte da Comunidade Internacional, no entanto, havia levado a um cenário de isolamento e sanções econômicas sobre o país árabe.

A entrada do Brasil na empreitada acontece após indicativo do presidente norte-americano Barack Obama, em um encontro do G-20 em julho de 2009. A tentativa brasileira de solução para o impasse do Irã é fruto, portanto, de uma abordagem da Casa Branca. Não faz sentido, assim, a narrativa de que o governo Lula estivesse se afastando radicalmente dos Estados Unidos, como parte da imprensa brasileira retratou. A possibilidade de concretização de algum tipo de acordo, após o fracasso das negociações anteriores, seria uma oportunidade para - Brasil de apresentar "uma contribuição inédita para o Sistema Internacional" (CONTIERI et al., 2015, p.8). Além do Brasil, a Turquia também foi instada a se envolver no assunto.

Após o gesto de Obama, no entanto, houve mudanças na postura norteamericana. Ao contrário do presidente, a secretária de Estado Hillary Clinton se mostrou irredutível quanto a um diálogo com Teerã. Na opinião de Amorim, havia uma "dualidade de opiniões", a seu ver expressa pelo "fato evidente de que Hillary perseguia uma agenda política própria" (AMORIM, 2015, p.63).

O resultado das negociações turco-brasileiras com o Irã foi a Declaração de Teerã, em 17 de maio de 2010. No acordo, constava a obrigação do Irã de depositar mil e duzentos quilos de urânio levemente enriquecido (LEU) na Turquia e de receber de volta, em até um ano, cento e vinte quilos de combustível para o Reator Nuclear de Pesquisas de Teerã. O acordo reconhecia o direito do Irã de desenvolver-se nuclearmente para fins pacíficos e tecnológicos. Pode-se dizer que a Declaração de Teerã se tornou realidade "em virtude do êxito das diplomacias brasileira e turca em compreender as particularidades da República Islâmica" (DA SILVA \& LEÃES, 2014, p.149).

No Brasil, a Declaração de Teerã sofreu duras críticas da mídia e até mesmo de parte do próprio corpo diplomático, que classificava as ações de Lula e Amorim como "antissionistas", "megalomaníacas" e "antiamericanas" (VIDAL, 2013, p.41). Ao fim, o documento foi ignorado pelas potências do Conselho de Segurança. As sanções econômicas ao Irã permaneceram e foram ampliadas, como uma forma de impor retaliações ao país pelo desenvolvimento do programa nuclear (CONTIERI et al., 2015, p.12). Brasil e Turquia votaram contra a resolução que ampliava as sanções. 
Seja por interesse em opor sanções econômicas ao Irã a qualquer custo, seja por medo do crescimento das potências regionais em questão ou seja por mera insensibilidade- o que, verdadeiramente, não se acredita ter sido o caso-, é certo que estes Estados provaram ter em suas palavras e os seus planos uma gigantesca deficiência de credibilidade. O desempenho do Brasil, bem como da Turquia, ao ir de encontro aos princípios mais básicos do direito internacional, da cordialidade e da polidez, mostraram-se, muito mais do que meramente adequados, simplesmente eficazes (CONTIERI et al., 2015, p.14).

Vale ressaltar que as diretrizes do acordo estavam em pleno atendimento aos requisitos desejados primeiramente pelos Estados Unidos. Visto que um novo acordo foi pensado em 2013, ainda com Obama como presidente e desta vez sem a participação do Brasil, é possível pensar que o recuo em 2010 se deu para impedir um protagonismo de países emergentes como Brasil e Turquia no cenário internacional.

É difícil avaliar o impacto e o legado da Declaração de Teerã, uma vez que esta jamais entrou em vigor (CONTIERI et al., 2015, p.14). Há, no entanto, uma série de desdobramentos que podem ser compreendidos como um resultado positivo da ação brasileira. No ano seguinte, o Council on Foreign Relations dos Estados Unidos (conselho ligado ao establishment norte-americano) recomendou a Washington uma revisão da política em relação ao Brasil, "de modo a contemplar melhor o novo status alcançado pelo país". O relatório era assinado por importantes figuras relacionadas à diplomacia norte-americana e apoiava a inclusão do Brasil como membro permanente no Conselho de Segurança (AMORIM, 2015, p.102).

O relatório foi solenemente ignorado pela grande imprensa brasileira, fato que Celso Amorim abordou em um artigo intitulado $O$ complexo de vira-lata, na revista Carta Capital, em 25 de julho de 2011. Para ele, parte da elite "insiste em ver o Brasil como um país pequeno" ou, no máximo, médio (AMORIM, 2011). A visão de parte da imprensa e da elite brasileira reproduz, portanto, a mesma lógica que teria levado as potências do Conselho de Segurança a recuarem sobre o acordo em 2010.

Em entrevista gravada concedida ao programa Espaço Público da TVT em janeiro de 2016, Marco Aurélio Garcia, chefe da Assessoria Especial da Presidência da República para Assuntos Internacionais no governo Lula, afirma que houve um entendimento, por parte das potências, de que a questão com o Irã era "briga de cachorro grande". Assim, um país emergente como o Brasil - "viralata" segundo a expressão popular - não poderia assumir um papel de protagonismo no tema. 


\section{O discurso dos editoriais de 0 Globo em oposição ao protagonismo brasileiro}

O objetivo de identificar a colonialidade presente no discurso jornalístico de O Globo visa complementar o entendimento, já mostrado anteriormente, de que há diferentes dimensões coloniais que vão da economia à produção do saber. Embora os grandes jornais insistam em reivindicar "neutralidade" e "isonomia", o próprio exercício dos editoriais já expõe que seus donos possuem opiniões e interesses.

Em relação ao Globo, ressalta-se que se trata de um dos maiores jornais impressos do país ao lado de Folha de São Paulo e O Estado de São Paulo, alternando com estes os maiores números de vendas de exemplares ${ }^{8}$. Pertencente às Organizações Globo, com uma vasta propriedade cruzada que inclui televisão, rádio e agora o meio digital, é simbólico e representativo do poder dos grandes conglomerados de mídia no Brasil. Pode-se dizer, assim, que o discurso de um editorial de O Globo é um exemplo consistente do pensamento político das elites brasileiras.

Ao longo do ano de 2010, foram publicados 21 editoriais no jornal O Globo que abordavam o tema do Irã de alguma forma. Destes, quatro citavam a questão brevemente, entre outros assuntos de política externa. Três editoriais tratavam das negociações de Teerã sem muitos comentários opinativos, apenas expondo os acontecimentos políticos do momento.

Por fim, 14 editoriais explicitavam o jornal O Globo em clara oposição à participação do Brasil no debate nuclear internacional e, principalmente, às conversas com o governo iraniano. Por vezes, os textos eram publicados ao lado da opinião de um articulista favorável à atuação do governo - normalmente, um deputado federal do PT, como Arlindo Chinaglia (SP) e Fernando Ferro (PE) ${ }^{9}$. É válido questionar porque, em nenhuma das ocasiões, foi procurado algum membro da comunidade epistêmica de Relações Internacionais para dar uma opinião que permitisse outros questionamentos e pontos de vistas além dos elencados pelo jornal, ainda que não fosse, necessariamente, defender a atuação do governo. As opiniões dos deputados, por mais qualificadas que fossem,

\footnotetext{
${ }^{8}$ Disponível em: https://diariodorio.com/o-globo-volta-a-ser-o-jornal-mais-vendido-do-brasil/. Acesso em: 01/08/19.

${ }^{9} \mathrm{O}$ artigo "Um acerto para a paz", de Arlindo Chinaglia (PT-SP), foi publicado ao lado do editorial "Suicídio diplomático", em 24 de maio de 2010. Já o artigo "Novo protagonismo", de Fernando Ferro (PT-PE), foi publicado juntamente com o editorial "Inepta e sem ética", em 23 de dezembro de 2010.
} 
poderiam ser mais facilmente ignoradas visto que pertencem a uma parte de interesse político.

A maior parte das críticas de O Globo se concentrava na aproximação do Brasil com países como o Irã, Cuba e Venezuela, todos considerados "antiamericanos". A escolha de Marco Aurélio Garcia para o cargo de assessor especial da Presidência da República para Assuntos Internacionais foi percebida pelos críticos como uma "presença indesejada", uma vez que o mesmo não era diplomata de carreira (CASARÕES, 2012, p.221). Notícias como a filiação de Celso Amorim ao PT em 2009 também contribuíram para ruídos de que o Itamaraty estivesse agindo de forma enviesada e ideológica (LOPES, 2011).

Figura 1 - Editorial "Brasil à deriva no apoio ao Irã"

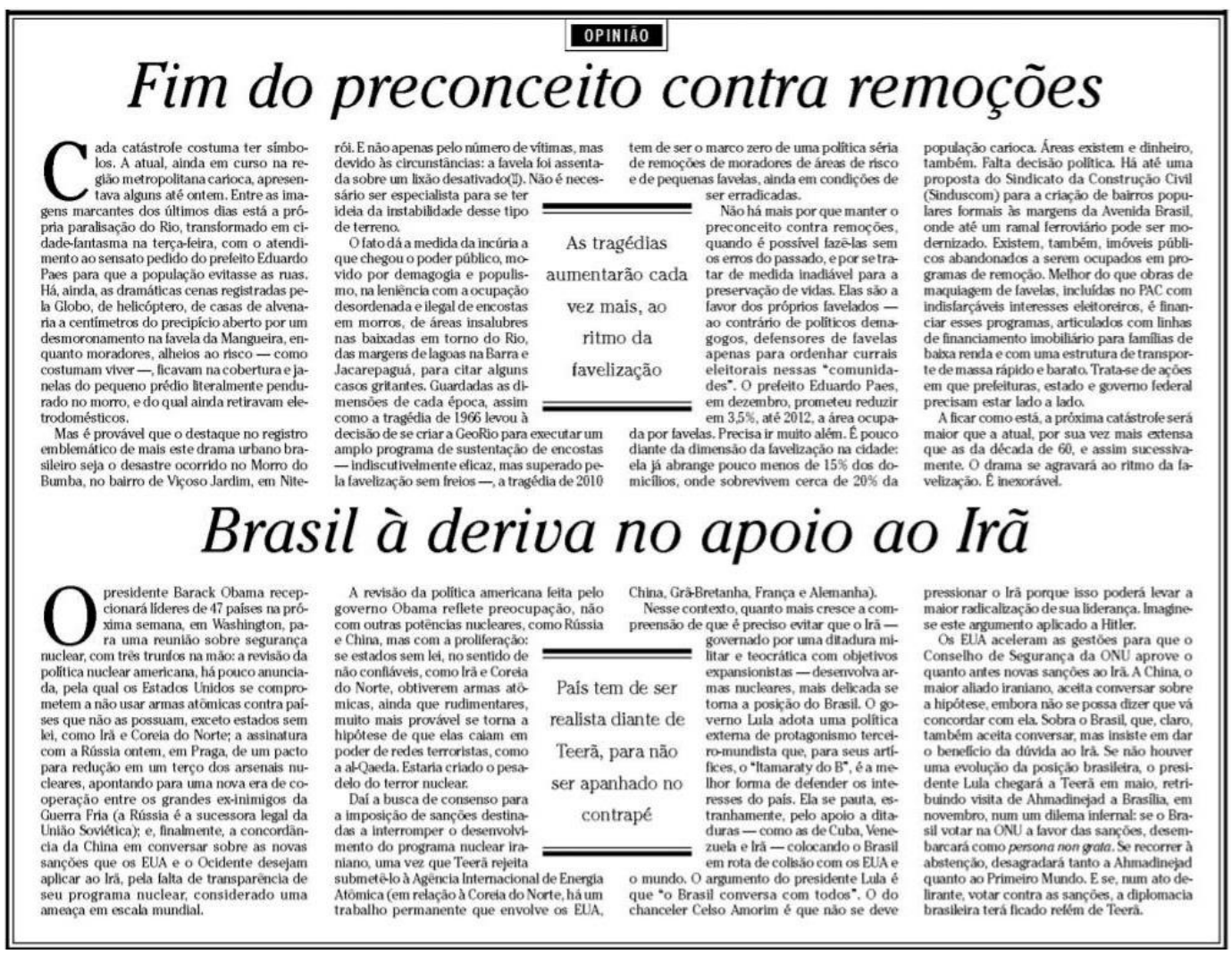

Fonte: Acervo Digital O Globo ${ }^{10}$

O artigo "Brasil à deriva no apoio ao Irã", publicado em 09 de abril de 2010, explicita a visão de $\mathrm{O}$ Globo de que o Itamaraty vinha agindo sob forte ideologização:

O governo Lula adota uma política externa de protagonismo terceiro-mundista que, para seus artífices, o "Itamaraty do B", é a melhor forma de defender os

10 Disponível em: https://acervo.oglobo.globo.com/. Acesso em: 12/07/19. 
interesses do país. Ela se pauta, estranhamente, pelo apoio a ditaduras - como as de Cuba, Venezuela e Irã - colocando o Brasil em rota de colisão com os EUA e o mundo ${ }^{11}$.

De acordo com O Globo, no editorial "Cegueira ideológica" (12 de abril de 2010) $)^{12}$, havia uma "interpretação corrente" de que a "diplomacia terceiromundista do governo Lula cumpria com a função, junto ao PT e aliados à esquerda, de compensar o mau humor com a política de estabilização econômica" conduzida pelo presidente, vista como "neoliberal" pelas bases petistas. Assim, a aproximação de Lula com Hugo Chávez e Fidel Castro serviria para compensar, aos olhos da esquerda, a presença de economistas considerados como neoliberais no governo, como Henrique Meirelles, presidente do Banco Central, e Antônio Palocci, ministro da Fazenda.

Figura 2 - "Cegueira ideológica"

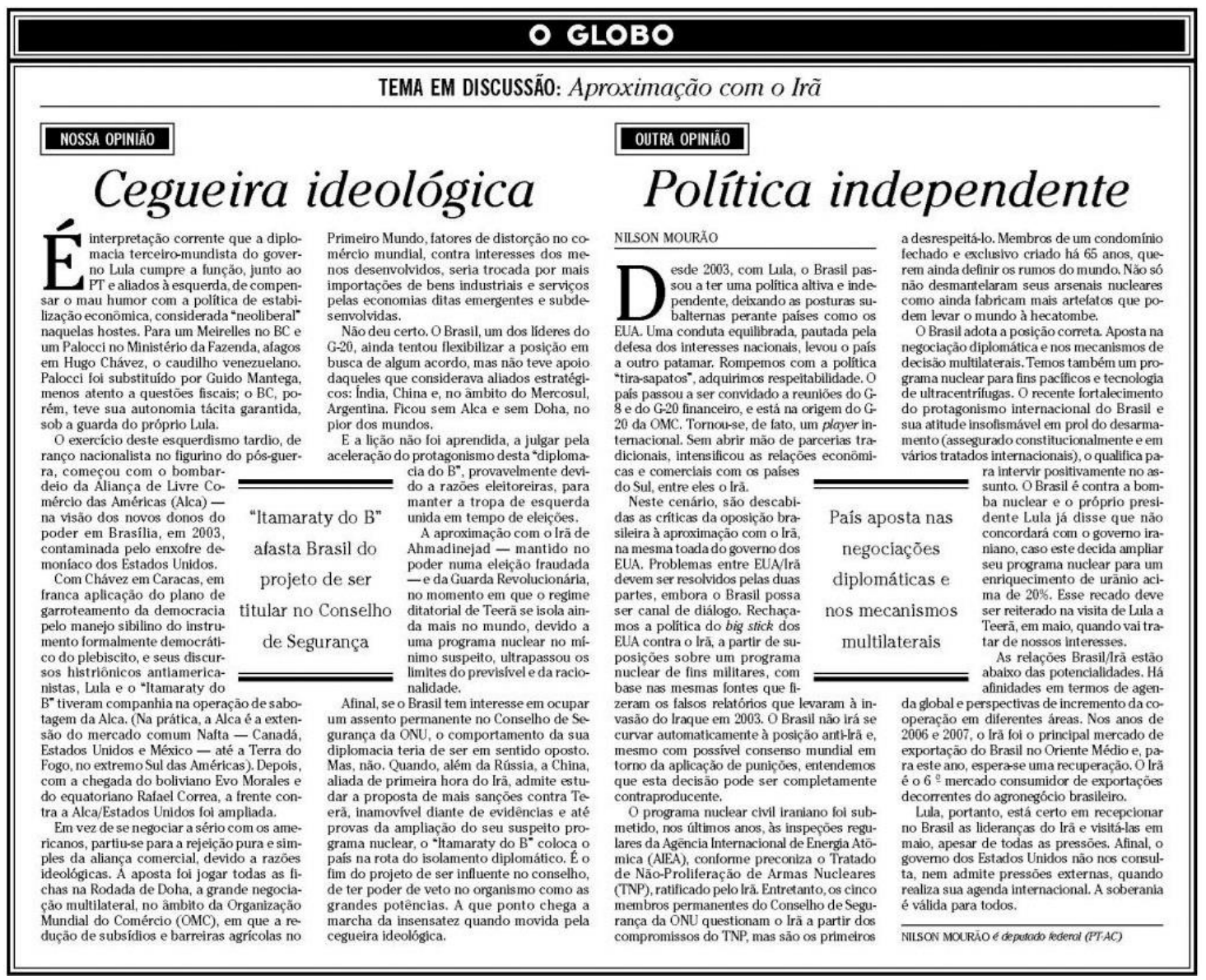

Fonte: Acervo Digital O Globo ${ }^{13}$

Em relação ao Conselho de Segurança da ONU, havia visões diferentes, por parte do governo e de seus críticos, sobre o caminho que levaria o Brasil a

\footnotetext{
11 Disponível em: https://acervo.oglobo.globo.com/. Acesso em: 12/07/19.

12 Disponível em: https://acervo.oglobo.globo.com/. Acesso em: 12/07/19.

${ }^{13}$ Disponível em: https://acervo.oglobo.globo.com/. Acesso em: 12/07/19.
} 
ganhar relevância suficiente para ocupar um assento permanente no Conselho, em uma eventual reforma. Enquanto Celso Amorim argumentava que a atuação brasileira no caso do Irã fortalecia as credenciais do país, a opinião do jornal O Globo era de que, se o interesse do governo era esse, "o comportamento da diplomacia teria de ser em sentido oposto". Para o jornal, a aproximação com a "ditadura iraniana" e o eventual fracasso no acordo de Teerã significava o "fim do projeto de ser influente no Conselho" e "de ter poder de veto como as grandes potências"14.

Enquanto Amorim entende que a autonomia e o protagonismo seriam as características que tornariam o Brasil relevante no cenário global, O Globo, por sua vez, compreende que o alinhamento com os Estados Unidos seria a melhor opção para ocupar uma vaga "entre os grandes". É válido questionar, inclusive, de que maneira o jornal enxergava a necessidade de se buscar maior presença do Brasil no cenário internacional. Em "Suicídio diplomático", publicado em 24 de maio de 2010, o jornal acusa uma "preocupação quase obsessiva - embora legítima - de aumento da influência mundial do Brasil"15.

\footnotetext{
14 Disponível em: https://acervo.oglobo.globo.com/. Acesso em: 12/07/19.

${ }_{15}$ Disponível em: https://acervo.oglobo.globo.com/. Acesso em: 12/07/19.
} 
Figura 3 - "Suicídio diplomático"

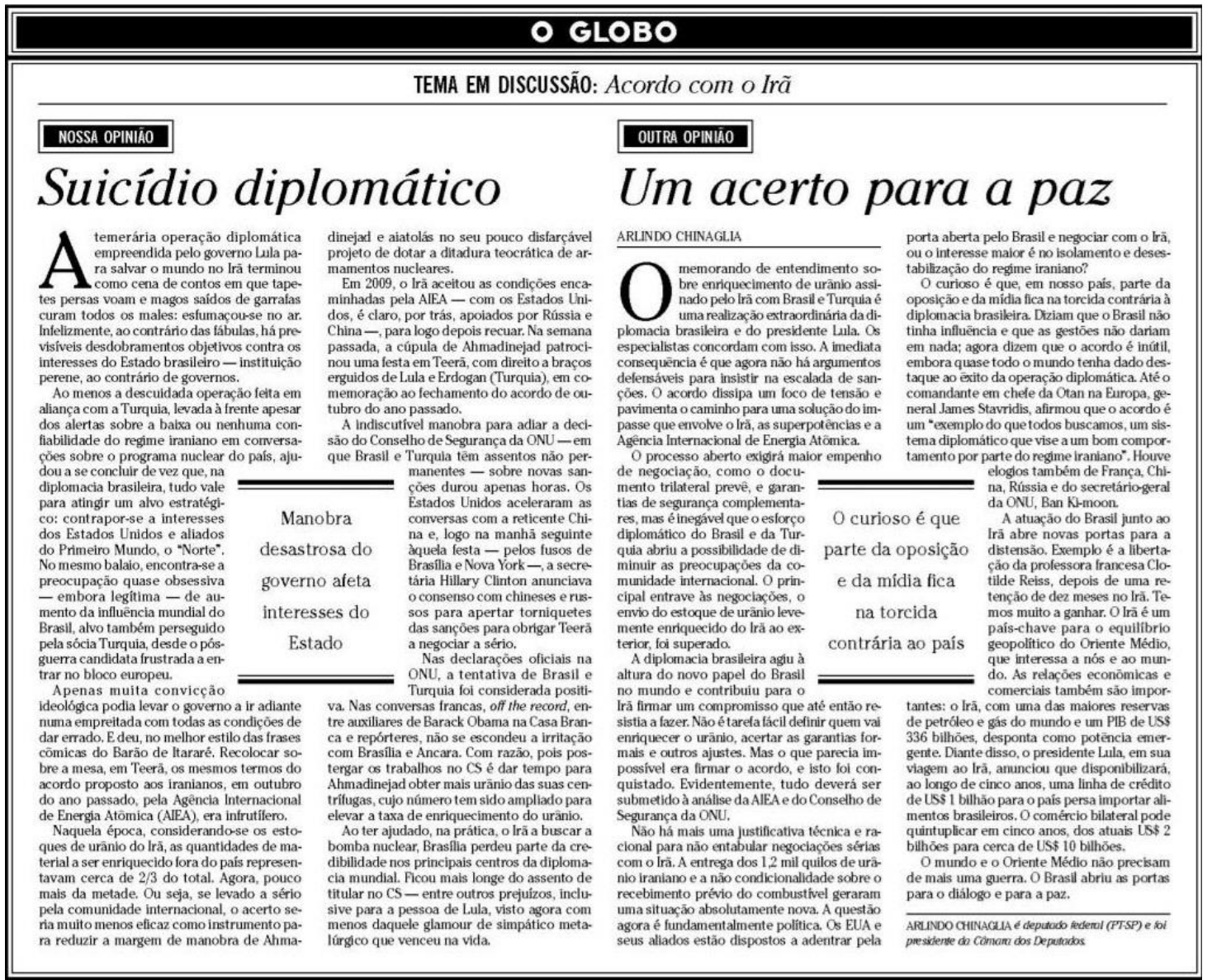

Fonte: Acervo Digital O Globo ${ }^{16}$

Em "Anatomia do fracasso da política externa" (20 de maio de 2010)17, O Globo afirma categoricamente que "a política externa não constará do balanço dos melhores momentos do governo Lula". Para o jornal, a diplomacia do presidente, por conta de uma "mistura de arrogância e autismo", havia "ultrapassado a autonomia de voo e perdido a sustentação"18.

\footnotetext{
16 Disponível em: https://acervo.oglobo.globo.com/. Acesso em: 12/07/19.

17 Disponível em: https://acervo.oglobo.globo.com/. Acesso em: 12/07/19.

18 Disponível em: https://acervo.oglobo.globo.com/. Acesso em: 12/07/19.
} 
Figura 4 - "Anatomia do fracasso da política externa"

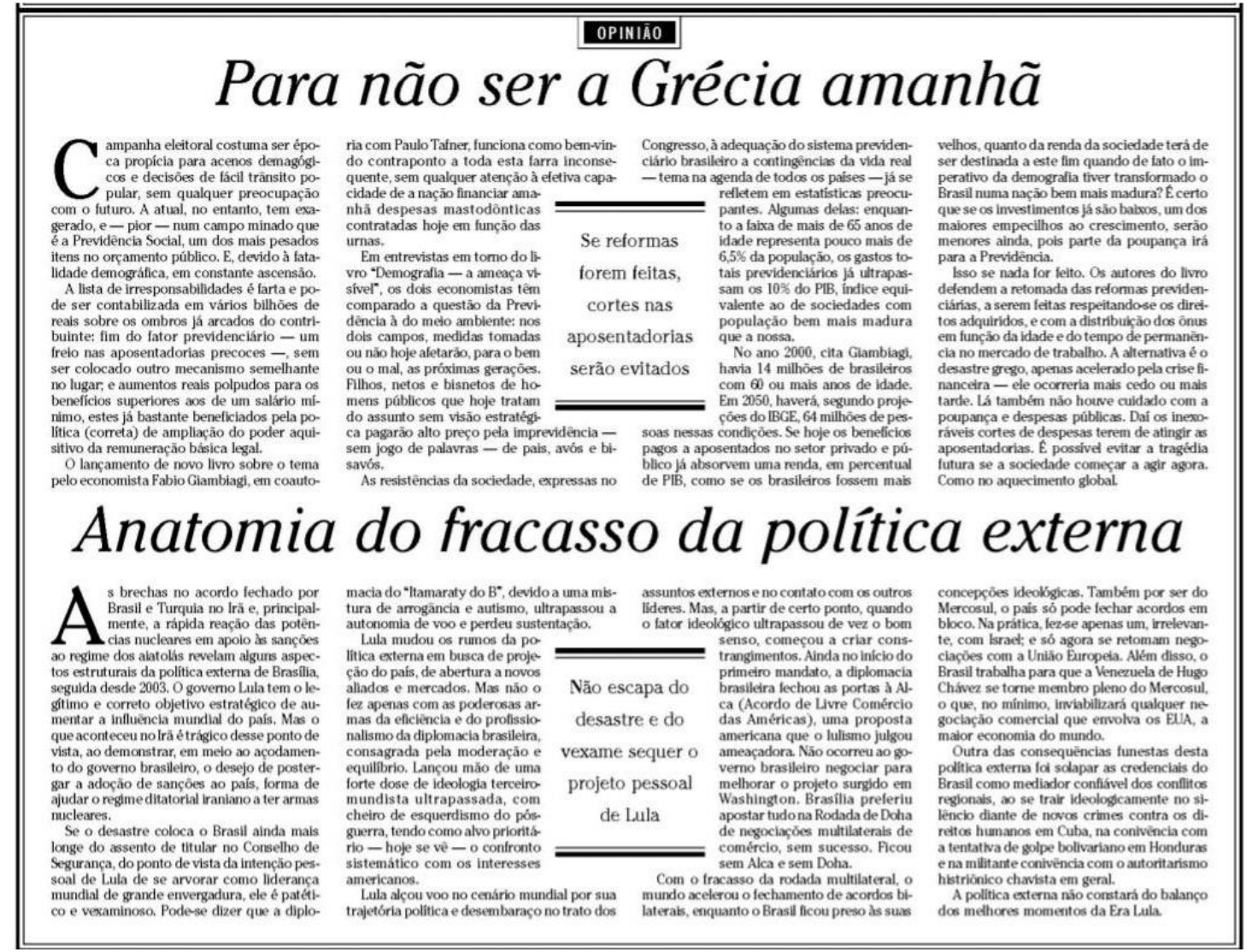

Fonte: Acervo Digital O Globo ${ }^{19}$

Em "Inepta e sem ética", artigo publicado em 23 de dezembro de $2010^{20}$, O Globo faz um balanço da Era Lula e Amorim na política externa brasileira. O jornal afirma: "Encerra-se o ciclo de uma diplomacia inepta, leniente na defesa dos interesses da nação - vide expropriação de bens da Petrobras - e sem ética nos direitos humanos. Na visão do grupo, o governo do PT havia investido em uma "arcaica diplomacia Sul-Sul, movida a um míope antiamericanismo"21.

\footnotetext{
${ }^{19}$ Disponível em: https://acervo.oglobo.globo.com/. Acesso em: 12/07/19.

20 Disponível em: https://acervo.oglobo.globo.com/. Acesso em: 12/07/19.

21 Disponível em: https://acervo.oglobo.globo.com/. Acesso em: 12/07/19.
} 
Figura 5 - "Inepta e sem ética"

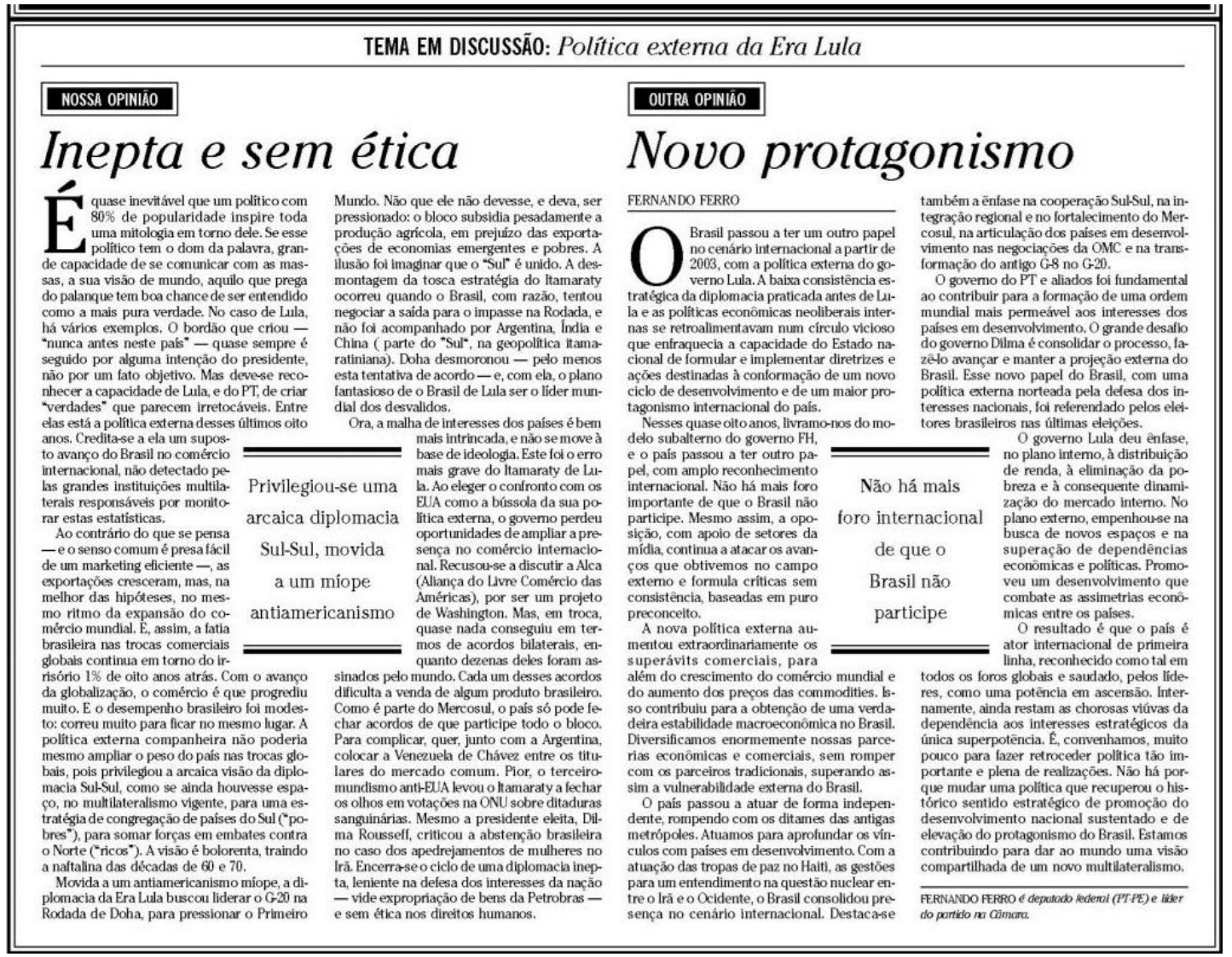

Fonte: Acervo Digital O Globo 22

É possível identificar a colonialidade no discurso dos editoriais de O Globo ao se tratar a cooperação Sul-Sul como uma iniciativa arcaica e ao se defender, nitidamente, um maior alinhamento com a política externa de Washington. $\mathrm{Na}$ opinião do jornal, se havia o desejo de tornar o Brasil um país influente no mundo, não deveria se pensar, em hipótese alguma, em contrariar os interesses norteamericanos.

É interessante confrontar essa visão com algumas das citações internacionais a Lula e Celso Amorim. O articulista David Rothkopf, da revista Foreign Policy, escreveu um artigo em outubro de 2009 intitulado "O maior chanceler do mundo", em referência a Amorim ${ }^{23}$. No texto, o autor afirma que Amorim "orquestrou uma transformação do papel mundial do Brasil quase sem precedentes históricos" e que era "o ministro do exterior mais bem sucedido do planeta” à época. Em 30 de novembro de 2010, Amorim recebeu uma premiação

22 Disponível em: https://acervo.oglobo.globo.com/. Acesso em: 12/07/19.

${ }^{23}$ Disponível em: https://foreignpolicy.com/2009/10/07/the-worlds-best-foreign-minister/. Acesso em: $11 / 07 / 2019$. 
em Washington, nos Estados Unidos, como sexto lugar na lista dos 100 pensadores globais do ano de 2010, elaborada pela revista Foreign Policy ${ }^{24}$.

Vale ressaltar que, em relação ao Acordo de Teerã, também houve relevantes manifestações positivas da imprensa internacional. Dias depois da assinatura do acordo, um editorial do jornal francês Le Monde definia o acontecimento como um marco, que certamente seria lembrado pelos livros de História (AMORIM, 2015, p.93). Articulistas, como Phillip Stephens, do Financial Times, também escreveram linhas elogiosas à atuação proativa de Brasil e Turquia (AMORIM, 2015, p.87). No Brasil, por sua vez, O Globo publicava editoriais que classificavam o acordo como "fracasso", "suicídio" e "derrota" 25.

É necessário destacar que as comparações feitas acima com veículos de comunicação estrangeiros não objetivam posicioná-los com superioridade ou razão, até mesmo porque a crítica internacional também não foi unânime em referência ao assunto. No entanto, é relevante expor que, em contraponto a um discurso quase uníssono da mídia brasileira, havia um debate mais "equilibrado" na imprensa estrangeira. Como já foi abordado a respeito da colonialidade e sua presença no jornalismo brasileiro, é o caso de reforçar o argumento de Chiumbu (2016, p.421) de que a mídia pode se localizar geograficamente na periferia, porém articular questões que afetam essa periferia a partir dos lócus do Ocidente.

É importante destacar também que O Globo não é o único jornal a ter se posicionado em forte contrariedade à diplomacia do governo Lula. A Folha de S.Paulo e o Estado de S.Paulo, os dois maiores jornais impressos do país ao lado de $O$ Globo, também utilizaram seus editoriais para criticar aspectos diversos da política externa brasileira. Para Pieranti (2009, p.10), a liberdade de imprensa no Brasil "sempre esteve vinculada a interesses, interpretações pouco claras e limitações". A concentração de mídia nas mãos de poucas organizações familiares "promove um ambiente hostil para a diversidade política" e permite que estas organizações se sintam como "agentes políticos por direito próprio", dadas sua influência política e a "ausência de um sólido arcabouço regulatório" (PIERANTI, 2009, p.10).

Ainda que os meios de comunicação sejam comerciais, tornaram-se dependentes de governos e financiamento público por conta das circunstâncias

\footnotetext{
${ }^{24}$ Disponível em: https://noticias.uol.com.br/internacional/ultimas-noticias/2010/11/29/celso-amorime-eleito-6-pensador-global-mais-importante-de-2010-em-ranking-da-foreign-policy.htm (Acesso em: 11/07/19).

${ }^{25}$ Referência aos seguintes editoriais: "Anatomia do fracasso da política externa", 20 de maio de 2010, p.6; "Suicídio diplomático", 24 de maio de 2010, p.6; "Uma derrota desnecessária do Brasil", 10 de junho de 2010, p.6.
} 
históricas, "o que resulta em uma baixa qualidade de eficiência regulatória e um alto grau de interferência no jornalismo que inibe o exercício de seu papel de cão de guarda" (ALBUQUERQUE, 2017, p.3).

"Padrões colusivos" de relacionamento entre proprietários privados de mídia e o Estado são um fenômeno comum não só no Brasil, mas na maior parte da América Latina. Este quadro é tensionado quando são eleitos representantes que não estão "em conformidade com os critérios das elites do que a democracia deveria ser" (ALBUQUERQUE, 2017, p.3). De acordo com Albuquerque (2017), a grande mídia cumpriu com um papel de "sistemática oposição" em muitos países da América Latina na década de 2000, quando diversos partidos de esquerda chegaram ao poder na região.

No caso da eleição de Lula no Brasil, Casarões (2012, p.221) afirma que a eleição do ex-metalúrgico levou "a uma grande convergência de conteúdo na mídia de massa - contra o governo recém-eleito". Acusações feitas pelos opositores do governo - personalismo excessivo de Lula na diplomacia, ideologia terceiro-mundista e antiamericanismo - foram "reproduzidas, ou até mesmo criadas, pelos jornais" (CASARÕES, 2012, p.221).

\begin{abstract}
Quando Luiz Inácio Lula da Silva tomou posse em janeiro de 2003, ele decidiu tornar as relações externas do Brasil tanto um instrumento para o desenvolvimento quanto uma fonte de prestígio - internamente e no exterior. Nunca antes a política externa estivera tão perto da vida quotidiana dos cidadãos. Ela também se tornou uma fonte de descontentamento (e uma oportunidade) para oposição ao governo Lula. De embaixadores aposentados a estudiosos de renome, de políticos a jornalistas, críticos frequentemente apareceram nas páginas de jornais e revistas, em artigos e editoriais de opinião, ressaltando gafes e enganos do governo em assuntos estrangeiros (CASARÕES, 2012, p. 212).
\end{abstract}

Pode-se dizer que não é a primeira vez que a grande mídia brasileira atua como oposição à política externa do governo. Albuquerque (2017) lembra a Política Externa Independente dos governos Jânio Quadros e João Goulart, vista como uma ameaça comunista nos tempos de Guerra Fria (ALBUQUERQUE, 2017, p.10).

Como afirma Guimarães (2006), a maneira como se configurou a inserção da economia brasileira no capitalismo mundial fez com que setores beneficiados pela concentração de renda no país estejam explicitamente vinculados ao sistema mundial de poder e seus desequilíbrios. Ao sentirem seus interesses ameaçados, esses atores não hesitam em utilizar-se dos canais midiáticos para manifestar seu descontentamento e discordância (GUIMARÃES, 2006). 
O embate entre uma visão "nacionalista" e outra "subalterna" tem suas raízes na própria formação histórica da América Latina. As sociedades latinoamericanas enfrentam o conflito "Ocidente versus o Resto" como uma questão interna, uma vez que suas elites "se percebem como os bastiões deslocados da civilização ocidental", imersos em uma realidade de cultura e práticas totalmente incompatíveis com o que enxergam como ideal (ALBUQUERQUE, 2017, p.2).

As elites latino-americanas padecem, assim, de uma "autopercepção como periférica", mesmo após dois séculos ou mais de independência. Não se enxergam nem como "ocidentais" nem como "não ocidentais", mas "definem-se essencialmente em termos de sua relação subordinada com o Ocidente" (ALBUQUERQUE, 2017, p.6).

É de extrema importância, assim, refletir não só sobre as condições econômicas estruturais que formam a imprensa no Brasil, mas também sobre a presença da "colonialidade do saber" na produção jornalística brasileira. Essa autopercepção periférica - que se relaciona diretamente com a expressão popular do "complexo de vira-lata" - se encaixa na lógica de submissão e inferioridade denunciada pelos autores decoloniais.

A grande imprensa na América Latina e no Brasil é marcada por uma similaridade discursiva, um chamado "pensamento único" influenciado pela mesma lógica colonial. Esse "pensamento único", de acordo com Ramonet (1995), seria "a tradução em termos ideológicos dos interesses de um conjunto de forças econômicas, particularmente as do capitalismo internacional".

Dentro desse contexto, dissemina-se a ideia de um jornalismo imparcial, que retrataria apenas os "fatos", sem uma posição ideológica. Para Halimi (1997, p.19), a independência do jornalismo é uma "lenda". Segundo o autor, há uma "ambiguidade" essencial na grande imprensa: embora ela desempenhe uma função pública, é, ainda assim, uma empresa privada - a exemplo de O Globo. "No limite, torna-se incompatível a busca de rentabilidade por parte da empresa jornalística com a função de informar e ser um espaço minimamente democrático de debate" (HALIMI, 1997, p.9). Concebe-se, portanto, que a grande imprensa atua como porta-voz das elites.

A colonialidade do saber a que se referiam os autores decoloniais está presente na grande imprensa do país, em suas mais variadas formas. Há a predominância de uma visão "vira-lata" de Brasil - ainda que, por vezes, disfarçada por argumentos patrióticos - que interdita debates sobre desenvolvimento, desigualdades e desequilíbrios no poder internacional. 
É válido questionar a quem serve a visão de país presente nos editoriais da grande imprensa. Em relação ao Acordo de Teerã, é preciso que se questionem as razões para crítica tão uníssona nos jornais brasileiros, uma vez que o tema em si era repleto de nuances. É também fundamental lembrar a atuação da mesma imprensa em governos anteriores e a sua relação com o poder. Diante disso, é inevitável pensar que a mídia agia de forma mais agressiva com o governo do Partido dos Trabalhadores exatamente por esse não estar associado, ao menos aparentemente, com o ideal de Brasil das elites.

\section{Considerações finais}

O objetivo deste artigo é despertar reflexões acerca dos discursos que permeiam nossa sociedade, nosso jornalismo e nosso debate político. Analisar um tema sob uma perspectiva decolonial representa compreender que o desequilíbrio social ultrapassa as estruturas econômicas e se faz presente nas esferas do saber, nas epistemes, na cultura. A colonialidade, enquanto processo que vai muito além dos colonialismos históricos, é extremamente atual. Como se observou com o desenvolvimento da pesquisa, a visão colonial está presente não só nas instituições financeiras, mas também nos meios diplomáticos, nos veículos de comunicação e nas academias.

Sem a pretensão de quebrar por completo essa hegemonia ocidental do saber, o presente artigo buscou dar preferência a bibliografias advindas do Sul Global, em especial da América Latina. Apesar de não se ter nenhum autor brasileiro inserido no Grupo Modernidade/Colonialidade, é possível considerar os trabalhos de vários autores - como Darcy Ribeiro, Theotônio dos Santos e Paulo Freire - como análogos ao pensamento decolonial. Uma possibilidade para um estudo futuro seria aprofundar essa relação.

Apesar da colonialidade evidente nos discursos de $O$ Globo aqui selecionados, com críticas sem grandes fundamentos como a do "antiamericanismo" ou a evocação superficial da defesa dos direitos humanos, é necessário pontuar que não está livre de críticas a atuação brasileira no Acordo de Teerã.

$\mathrm{Na}$ questão dos direitos humanos, é importante pontuar a hipocrisia com que o tema é levantado nas críticas à aproximação com países de governos autoritários. Aqui, por exemplo, é possível facilmente apontar a contradição entre quem coloca o Irã como Estado pária, mas é conivente com as violações cometidas pelo governo saudita, aliado de primeira hora dos Estados Unidos no Oriente Médio. 
Em que pese essa instrumentalização do tema, é válido também questionar, ao menos no âmbito da diplomacia, se o Brasil (enquanto país que se propunha líder das nações emergentes) não deveria dar mais atenção a uma questão ainda tão problemática nos países do Sul Global. A postura em relação a violações graves feitas por governos como Irã, Angola, Zimbábue e outros mereceria, ao menos, maior reflexão. Nesse sentido, é importante destacar positivamente a mediação diplomática do governo Lula no intuito de resolver conflitos na América do Sul, como no caso da Venezuela em 2003.

Sabendo-se que tanto a perspectiva teórica decolonial quanto a interseção entre Mídias e Relações Internacionais são ainda escassas na academia no Brasil, o artigo busca trazer uma contribuição, sem a pretensão de reinventar olhares sobre tais questões. A opção de trazer como objeto de estudo um tema recente da política externa do país parte também da compreensão de que é preciso produzir mais conteúdo acadêmico sobre questões brasileiras e periféricas. A teoria decolonial, portanto, é a chave para esse entendimento.

Ainda que seja difícil falar em uma completa decolonialidade, uma vez que as bibliografias de ambas as comunidades epistêmicas são dominadas por autores anglo-saxões e mesmo o pensamento do autor deste artigo é já influenciado por uma visão ocidental, é válido e necessário se buscar mais referências decoloniais e advindas do Brasil, América Latina, África, entre outras regiões. Como é dito por Gonçalves \& Valente (2015), a autonomia intelectual é um dos principais passos para a autonomia de um país. Pensar um Brasil soberano e ativo no cenário global passa, também, por valorizar a cultura e o saber brasileiros.

\section{Referências bibliográficas}

ALBUQUERQUE, Afonso. Protecting democracy or conspiring against it? Media and politics in Latin America: A glimpse from Brazil. In: Journalism. Rio de Janeiro: 2017. p.906-922.

AMORIM, Celso. Conversas com jovens diplomatas. São Paulo: Benvirá, 2011. 616p.

O complexo de vira-lata. Revista Carta Capital, Rio de Janeiro, 25 de julho de 2011. Disponível em: https://www.viomundo.com.br/voce-escreve/celso-amorim-aobsessao-e-o-complexo-de-vira-lata.html. Acesso em: 28/05/2019.

A política externa do governo Lula: dois anos. Revista Plenarium, 2005. Disponível em: http://www.itamaraty.gov.br/pt-BR/discursos-artigos-e-entrevistascategoria/7788-a-politica-externa-do-governo-lula-dois-anos-artigo-do-ministro-das- 
relacoes-exteriores-embaixador-celso-amorim-publicado-na-revista-plenarium. Acesso em: 17/05/2019.

Teerã, Ramalá e Doha: Memórias da Política Externa Ativa e Altiva. São Paulo: Benvirá, 2015. 520p.

BALLESTRIN, Luciana. América latina e o giro decolonial. In: Revista Brasileira de Ciência Política. Brasília: Instituto de Ciência Política da UnB, 2013. p.89-117.

BERRINGER, Tatiana. Bloco no Poder e política externa nos governos FHC e Lula. Campinas. 2014. 241p. Tese (Doutorado em Ciência Política) - Instituto de Filosofia e Ciências Humanas da Universidade Estadual de Campinas.

BURITY, Caroline Rangel Travassos. A influência da mídia nas relações internacionais: um estudo teórico a partir do conceito de diplomacia midiática. In: Revista Contemporânea. Rio de Janeiro: UERJ, 2013. p.164-177.

CASARÕES, Guilherme Stolle Paixão. A mídia e a política externa no Brasil de Lula. In: Austral: Revista Brasileira de Estratégia e Relações Internacionais. Rio Grande do Sul: UFRGS, 2012. p.211-236.

CHIUMBU, Sarah. Media, Race and Capital: A Decolonial Analysis of Representation of Miners' Strikes in South Africa. In: African Studies. Johannesburg: Human Sciences Research Council (HSRC), 2016. p.417-435.

CONTIERI, Bruna Leão Lopes et al. Declaração de Teerã: A Importância da Mediação Brasileira para a Segurança Internacional Frente aos Desafios da Proliferação Nuclear. Rio Grande do Sul: 2015. 16p.

DA SILVA, André Luiz Reis; LEÃES, Ricardo Fagundes. A Convergência TurcoBrasileira na Declaração de Teerã. In: Mural Internacional. Rio de Janeiro: UERJ, 2014. p.148-162.

ESCOBAR, Arturo. La invención del Tercer Mundo: Construcción y deconstrucción del desarrollo. Caracas: Fundación Editorial el perro y la rana, 2007. 424p.

ESPANHOL, Carla de Oliveira. O pensamento decolonial como perspectiva contrahegemônica nos debates teóricos das relações internacionais. In: 6 Encontro da ABRI, 2017, Belo Horizonte. Anais eletrônicos do 6ํㅡㄹ Encontro da ABRI, 2017. 14p.

FARIA, Carlos Aurélio Pimenta de. Opinião pública e política externa: insulamento, politização e reforma na produção da política exterior do Brasil. In: Revista Brasileira de Política Internacional. Brasília: Instituto Brasileiro de Relações Internacionais, 2008. p.80-97.

FONTES, Pablo et al. A interdisciplinaridade nos estudos das Relações Internacionais: A contribuição da Comunicação Social aos estudos sobre Mídia e Política Externa. In: Monções: Revista de Relações Internacionais da UFGD. Dourados: UFGD, 2017. p.443-467.

GILBOA, Eytan. Diplomacy in the media age: three models of uses and effects. In: Diplomacy \& Statecraft. Londres: Frank Cass, 2001. 24p. 
GONÇALVES, Williams; VALENTE, Leonardo. O monopólio das teorias anglosaxões no estudo das Relações Internacionais. In: Século XXI - Revista de Relações Internacionais. Porto Alegre: ESPM Sul, 2015. p.53-69.

GROSFOGUEL, Ramon. The epistemic decolonial turn beyond political-economy paradigms. In: Cultural Studies. Londres: Routledge, 2007. p.211-223.

GUIMARÃES, Samuel Pinheiro. Desafios brasileiros na era dos gigantes. Rio de Janeiro: Contraponto, 2006. 456p.

HALIMI, Serge. Os novos cães de guarda. Brasil: Vozes, 1997. 152p.

LESSA, Mônica et al. Centro e Periferia: os desafios da expansão dos Cursos de Relações Internacionais no Brasil. In: Revista de Sociologia e Política, 2019, no prelo. 31p.

LIPPMANN, Walter. Opinião pública. Rio de Janeiro: Vozes, 2008. 352p.

LOOMBA, Ania. Colonialism/Postcolonialism. Londres: Routledge, 1998. 312p.

LOPES, Dawisson Belém. A política externa brasileira e a "circunstância democrática": do silêncio respeitoso à politização ruidosa. In: Revista Brasileira de Política Internacional. Brasília: Instituto Brasileiro de Relações Internacionais, 2011. p.67-86.

MORENO, Marta Fernandez. Um (des)encontro de saberes: teorias da Modernização e teoria das Relações Internacionais. In: Carta Internacional. Rio de Janeiro: ABRI, 2012. p.35-52.

MIGNOLO, Walter. Historias locales/disenos globales: colonialidad, conocimientos subalternos y pensamiento fronterizo. Madrid: Princeton University Press, 2003. 452p.

PIERANTI, Octavio Penna. Regulação da comunicação de massa: novas perspectivas teóricas e redefinições conceituais para o contexto brasileiro. Rio de Janeiro. 2009. 416p. Tese (Doutorado em Administração) - FGV.

QUIJANO, Aníbal. Colonialidad del poder y clasificación social. In: Journal of worldsystems research. Pittsburgh: University of Pittsburgh Press, 2000. p.342-386.

RAMONET, Ignacio. O pensamento único e os novos senhores do mundo. In: Le Monde Diplomatique. Paris: 1995. 27p.

ROSSONE DE PAULA, Francine. The emergence of Brazil to the global stage: ascending and falling in the international order of competition. New York: Routledge, 2018. 172p.

ROTHKOPF, David. The world's best foreign minister. Foreign Policy, Washington DC, 7/10/2009. Disponível em: https://foreignpolicy.com/2009/10/07/the-worldsbest-foreign-minister/. Acesso em: 11/07/2019.

VALENTE, Leonardo. Política externa na era da informação. Rio de Janeiro: Editora Revan, 2007. 192p. 
VIDAL, Camila Felix. O protagonismo brasileiro diante da Declaração de Teerã. In: Revista Conjuntura Austral. Rio Grande do Sul, 2013. p.41-61.

\section{Sites consultados:}

O GLOBO. Acervo Digital O Globo. Disponível em:

https://acervo.oglobo.globo.com/. Acesso em: 12/07/19. 